(C) Dereito Vol.28, n01:85-107 (Xaneiro-Xuño, 2019) • ISSN 1132-9947

\title{
O SISTEMA PORTUGUÊS DA AÇÃO COLETIVA
}

El sistema portugués de la acción colectiva

DOI: http://dx.doi.org/10.15304/dereito.28.1.5615

\author{
Tiago BRANCO DA COSTA \\ Investigador do Centro de Investigação em Justiça e Governação Universidade \\ do Minho \\ tfbrancoc@gmail.com
}

\section{Resumen}

El derecho de petición y derecho de acción colectiva surge en la legislación portuguesa como derecho constitucionalmente consagrado. En efecto, en Portugal, está en vigor la Ley n. ${ }^{0}$ 83/95, de 31 de agosto, por la que se establece el régimen del derecho a la participación y procedimiento de la acción colectiva.

A pesar de que no todos los ordenamientos jurídicos consagren un régimen propio que regule directa y específicamente los términos de este derecho fundamental, lo cierto es que a nivel de la Unión Europea se han reunido esfuerzos para alcanzar un cierto nivel de regulación y armonización de estas materias entre los distintos Estados miembros.

Para corroborar precisamente esta intención tenemos la Recomendación de la Comisión 2013/396/UE, de 11 de junio de 2013 y la Propuesta de Directiva del Parlamento Europeo y del Consejo relativa a las acciones representativas para la protección de los intereses colectivos de los consumidores y por la que se deroga la Directiva 2009/22/CE.

Este 'nuevo mundo' plantea varios retos jurídicos que los Estados miembros tendrán que superar, combinando las directrices emitidas por la Unión Europea, por un lado, con sus identidades propias y culturas jurídicas, por otro.

Palabras clave: Acción colectiva; Presupuestos; Indemnización; Recomendación 2013/396/EU; Propuesta de Directiva.

\section{Abstract}

The right of petition and right of collective redress arises in portuguese law as a constitutionally consecrated right. In effect, in Portugal, Law no. $83 / 95$, of August 31, establishes the regime of the right of procedural participation and popular action.

Regardless of the fact that not all legal systems lay down a system of their own which directly and specifically governs the terms of this fundamental right, it is certain that at European Union level efforts have been made to achieve a certain level of regulation and harmonization between the various Member States.

To corroborate precisely this intention we have Commission Recommendation 2013/396/EU, of 11 June 2013 and the Proposal for a Directive of the European Parliament and of the Council on representative

Recibido: 28/01/2019. Aceptado: 15/05/2019. 
actions for the protection of the collective interests of consumers, and repealing Directive 2009/22/EC.

This new world promises several legal challenges that Member States will have to be able to overcome by combining the European Union's guidelines with its own legal identities and cultures.

Keywords: Collective action; Legal assumptions; Reparation; Recommendation 2013/396/EU; Proposal for a Directive.

\section{Resumo}

O direito de petição e direito de ação popular surge no direito português enquanto direito constitucionalmente consagrado. Com efeito, em Portugal, vigora a Lei n.o 83/95, de 31 de agosto, que estabelece o regime do direito de participação procedimental e de ação popular.

Não obstante $O$ facto de nem todos os ordenamentos jurídicos consagrarem um regime próprio que regule direta e especificamente os termos deste direito fundamental, o certo é que ao nível da União Europeia têm-se congregado esforços no sentido de alcançar um certo nível de regulação e harmonização destas matérias entre os vários Estados-Membros.

A corroborar precisamente esta intenção temos a Recomendação da Comissão 2013/396/UE, de 11 de junho de 2013 e a Proposta de Diretiva do Parlamento Europeu e do Conselho relativa a ações coletivas para proteger os interesses coletivos dos consumidores e que revoga a Diretiva 2009/22/CE.

Este mundo novo promete vários desafios jurídicos que os EstadosMembros terão de ser capazes de ultrapassar, conjugando as diretrizes emanadas pela União Europeia com as suas próprias identidades e culturas jurídicas.

Palavras chave: Ação coletiva; Pressupostos; Indemnização; Recomendação 2013/396/UE; Proposta de Diretiva.

\section{SUMARIO}

1.- INTRODUCCIÓN. 2.- LA LEY N. 0 83/95, DE 31 DE AGOSTO: CONSIDERACIONES GENERALES. 3.- LA TITULARIDAD DEL DERECHO DE ACCIÓN COLECTIVA Y LA LEGITIMACIÓN ACTIVA.- 4.- EL EJERCICIO DEL DERECHO DE ACCIÓN COLECTIVA. 5.- LA PETICIÓN (PETITUM) EN LA ACCIÓN COLECTIVA. 6.- LA RESPONSABILIDAD CIVIL OBJETIVA Y LA RESPONSABILIDAD CIVIL SUBJETIVA. 7.- LA DECISIÓN JUDICIAL SOBRE LA ACCIÓN COLECTIVA Y SUS EFECTOS. 8.- LA RECOMENDACIÓN DE LA COMISIÓN 2013/396/UE, DE 11 DE JUNIO DE 2013 Y LA PROPUESTA DE DIRECTIVA DEL PARLAMENTO EUROPEO Y DEL CONSEJO RELATIVA A LAS ACCIONES DE REPRESENTACIÓN PARA LA PROTECCIÓN DE LOS INTERESES COLECTIVOS DE LOS CONSUMIDORES Y POR LA QUE SE DEROGA LA DIRECTIVA 2009/22/CE. 9.- LA ACCIÓN COLECTIVA EN EL ÁMBITO DEL REGLAMENTO GENERAL SOBRE LA PROTECCIÓN DE DATOS. 10.- CONCLUSIÓN. 11.- BIBLIOGRAFÍA.

\section{SUMMARY}


1.- INTRODUCTION. 2.- LAW NO. 83/95, OF AUGUST 31: GENERAL CONSIDERATIONS. 3.- THE OWNERSHIP OF THE RIGHT OF COLLECTIVE REDRESS AND ACTIVE LEGITIMACY. 4.- THE EXERCISE OF THE RIGHT OF COLLECTIVE REDRESS. 5.- THE APPLICATION IN CLASS ACTIONS. 6.OBJECTIVE CIVIL LIABILITY AND SUBJECTIVE CIVIL LIABILITY. 7.- THE JUDICIAL DECISION OF THE COLLECTIVE REDRESS AND ITS EFFECTS. 8.COMMISSION RECOMMENDATION 2013/396/EU OF 11 JUNE 2013 AND THE PROPOSAL FOR A DIRECTIVE OF THE EUROPEAN PARLIAMENT AND OF THE COUNCIL ON REPRESENTATIVE ACTIONS FOR THE PROTECTION OF THE COLLECTIVE INTERESTS OF CONSUMERS, AND REPEALING DIRECTIVE 2009/22/EC. 9.- COLLECTIVE ACTION UNDER THE GENERAL REGULATION ON DATA PROTECTION. 10.- CONCLUSION. 11.BIBLIOGRAPHY.

\section{SUMÁRIO}

1.- INTRODUÇÃO. 2.- A LEI N. ${ }^{\circ}$ 83/95, DE 31 DE AGOSTO: CONSIDERAÇÕES GERAIS. 3.- A TITULARIDADE DO DIREITO DE AÇÃO POPULAR E DA LEGITIMIDADE ATIVA. 4.- O EXERCÍCIO DO DIREITO DE AÇÃO POPULAR. 5.- O PEDIDO NA AÇÃO COLETIVA. 6.- A RESPONSABILIDADE CIVIL OBJETIVA E A RESPONSABILIDADE CIVIL SUBJETIVA. 7.- A DECISÃO JUDICIAL DA AÇÃO COLETIVA E OS SEUS EFEITOS. 8.- A RECOMENDAÇÃO DA COMISSÃ̃ 2013/396/EU, DE 11 DE JUNHO DE 2013 E A PROPOSTA DE DIRETIVA DO PARLAMENTO EUROPEU E DO CONSELHO RELATIVA A AÇÕES COLETIVAS PARA PROTEGER OS INTERESSES COLETIVOS DOS CONSUMIDORES E QUE REVOGA A DIRETIVA 2009/22/CE. 9.- A AÇÃO COLETIVA NO ÂMBITO DO REGULAMENTO GERAL SOBRA A PROTEÇÃO DE DADOS. 10.CONCLUSÃO. 11.- BIBLIOGRAFIA.

\section{INTRODUÇÃO}

A Constituição da República Portuguesa (CRP) consagra, no artigo 52.0, o direito de petição e direito de ação popular ${ }^{1-2}$.

Nos termos deste preceito legal, todos os cidadãos têm o direito de apresentar, individual ou coletivamente, aos órgãos de soberania, aos

\footnotetext{
${ }^{1} \mathrm{~A}$ ação popular é designada, nos diferentes ordenamentos jurídicos, de forma díspar, pelo que, ao longo do texto, utilizaremos indistintamente os seguintes termos: class actions, action de groupe, representative actions, test/model case procedings, ação coletiva.

${ }^{2}$ Vd. ALVES, João, "Ação popular: manifesta improcedência do pedido - parecer do Ministério Público", Revista do Ministério Público 148: Outubro: Dezembro 2016 pp.141149, p.141, "A ação popular tem como objeto a tutela de interesses difusos, o que compreende os interesses difusos stricto sensu, os interesses coletivos e os interesses individuais homogéneos"; SOUSA, Miguel Teixeira de, "Legitimidade Processual e Acção Popular no Direito do Ambiente", em Direito do Ambiente, Diogo Freitas do Amaral; Marta Tavares de Almeida (coord.), Oeiras, Instituto Nacional de Administração, 1994, pp.409-429, p.412, "Um interesse difuso corresponde a um direito juridicamente reconhecido e tutelado, cuja titularidade pertence a todos e cada um dos membros de uma comunidade ou grupo mas não é suscetível de apropriação individual por qualquer um desses membros."
} 
órgãos de governo próprio das regiões autónomas, ou a quaisquer autoridades, petições, representações, reclamações, ou queixas para defesa dos seus direitos, da Constituição, das leis ou do interesse geral e, bem assim, o direito de serem informados, em prazo razoável, sobre o resultado da respetiva apreciação ${ }^{3}$.

Ademais, é conferido a todos os cidadãos, pessoalmente ou através de associações de defesa dos interesses em causa, o direito de ação popular, nos casos e termos previstos na lei, incluindo o direito de requerer para o lesado ou lesados a correspondente indemnização. Este direito surge com o propósito de, designadamente, promover a prevenção, a cessação ou a perseguição judicial das infrações contra a saúde pública, os direitos dos consumidores, a qualidade de vida, a preservação do ambiente e do património cultural (al. a), do n. ${ }^{\circ} 3$, do artigo 52.0 , da CRP); e assegurar a defesa dos bens do Estado, das regiões autónomas e das autarquias locais (al. b), do n. ${ }^{\circ} 3$, do artigo 52.0, da CRP) ${ }^{4}$.

O direito de ação popular previsto pelo n. ${ }^{\circ} 3$ foi introduzido pela revisão de 1989, em substituição do n. ${ }^{\circ} 2$ do texto original, e posteriormente alterado pela revisão de $1997^{5}$.

Na senda de Jorge Miranda e Rui Medeiros, o direito de ação popular garante a todos os cidadãos o acesso aos tribunais para defesa de interesses supra-individuais, numa perspetiva de superação da tutela subjetiva ${ }^{6}$.

De facto, a tutela conferida pelo então artigo 52.0 da CRP será, prima facie, uma concretização do princípio da tutela jurisdicional efetiva (consagrada no artigo $20 .^{\circ}$, da CRP), mas será mais do que isso, no sentido em que se permite a todos os cidadãos que atuem como defensores de bens jurídicos de interesse comum para os indivíduos daquela comunidade ${ }^{7}$.

${ }^{3}$ Cfr. SOUSA, Miguel Teixeira de, "A Legitimidade Popular na Tutela dos Interesses Difusos, Lisboa, Lex, 2003, pp.70 e ss..

$4 \mathrm{Na}$ senda de REBELO, Marta, "A legitimidade popular para a efetivação de responsabilidades financeiras", em Estudos Jurídicos e Económicos em Homenagem ao Professor Doutor António de Sousa Franco, Vol. III, Paulo de Pitta e Cunha (coord.), Coimbra, Coimbra Editora, 2006, pp.285-299, p.287, "Tal como constitucionalmente configurado, o direito de ação popular é, então, um direito de natureza processual: reunidos os pressupostos legalmente estabelecidos, o ator popular poderá acionar um conjunto vasto de meios processuais, sem que esteja condicionado à utilização prévia necessária de qualquer outro meio judicial."

${ }^{5}$ Cf. MIRANDA, Jorge; MEDEIROS, Rui, "Constituição Portuguesa Anotada", Tomo I, 2.a edição, Coimbra, Coimbra Editora, 2010, p.1023.

6 Vd. MIRANDA, Jorge; MEDEIROS, Rui, "Constituição Portuguesa Anotada", op. cit., pp.1029 e ss..

7 Neste sentido, vd. CANOTILHO, J. J. Gomes; MOREIRA, Vital, "Constituição da República Portuguesa Anotada", Vol. I, 4. a edição, Coimbra, Coimbra Editora, 2007, p. 693, "o direito de ação popular (...) constitui, no fundo, uma «declinação» do direito de ação judicial (artigo $20{ }^{\circ}$ ), só que para defesa de certos bens constitucionalmente protegidos, no âmbito transindividual, não tendo o âmbito universal do direito de petição nem do direito de ação judicial comum". 
A Lei n. ${ }^{0}$ 83/95, de 31 de agosto, regulou no ordenamento jurídico português o direito de participação procedimental e de ação popular ${ }^{8}$.

A par desta regulamentação, tem-se discutido no contexto da União Europeia a afirmação deste direito de ação coletiva, nomeadamente no que respeita à defesa dos consumidores, sendo exemplo desse esforço a Recomendação da Comissão 2013/396/UE, de 11 de junho de 2013, e, mais recentemente, o «New Deal for Consumers», de 11 de abril de 2018, composto, por sua vez, por duas propostas de diretivas: (i) uma proposta de alteração da Diretiva do Conselho relativa às cláusulas abusivas nos contratos celebrados com os consumidores, da Diretiva em matéria de indicações dos preços dos produtos oferecidos aos consumidores, da Diretiva relativa às práticas comerciais desleais entre empresas e consumidores e da Diretiva relativa aos direitos dos consumidores; (ii) uma proposta sobre ações representativas para a proteção dos interesses coletivos dos consumidores e que revoga a Diretiva 2009/22/CE, relativa às ações inibitórias.

O nosso propósito é, precisamente, o de percorrer o regime legal português da ação coletiva (direito de ação popular), especialmente no domínio do direito civil, fazendo, sempre que oportuno e adequado, o paralelismo com outros sistemas jurídicos, tecendo as necessárias críticas ao sistema vigente e discutindo as alterações que têm vindo a ser introduzidas ao regime legal.

\section{A LEI N.० 83/95, DE 31 DE AGOSTO: CONSIDERAÇÕES GERAIS}

A Lei n. ${ }^{\circ} 83 / 95$, de 31 de agosto, conforme referimos supra, regula, no ordenamento jurídico português, o regime do direito de participação procedimental e de ação popular ${ }^{9}$.

${ }^{8}$ Este diploma legal veio a ser alterado pela Retificação n. ${ }^{\circ} 4 / 95$, de 12 de outubro e, mais tarde, pelo DL n. ${ }^{\circ} 214-\mathrm{G} / 2015$, de 02 de outubro.

9 Vd. ANDRADE, José Robin de, "A Acção Popular no Direito Administrativo Português", op. cit., p.4, onde se apresenta uma definição de ação popular, "será ela a modalidade de ação judicial para cuja propositura serão partes legítimas todos os indivíduos que, incluídos no «Populus», ou em categoria ampla aproximável, apresentarem como título da sua legitimidade um mero interesse genérico derivado da sua pertença à coletividade política".

Vd. ainda a definição de «tutela coletiva» apresentada pela Recomendação, "Para efeitos da presente recomendação, entende-se por: Tutela coletiva», i) um mecanismo jurídico que garanta a possibilidade de duas ou mais pessoas singulares ou coletivas, ou uma entidade com legitimidade para intentar uma ação representativa, pedirem coletivamente a cessação de um comportamento ilegal (tutela coletiva inibitória); ii) um mecanismo jurídico que assegure a possibilidade de duas ou mais pessoas singulares ou coletivas que aleguem terem sofrido danos numa situação de dano em massa, ou uma entidade com legitimidade para intentar uma ação representativa, pedirem coletivamente uma indemnização (tutela coletiva indemnizatória)"; e a Proposta de Diretiva, da qual consta a seguinte definição de «ação coletiva»: "ação destinada a proteger interesses coletivos dos consumidores, na qual estes não são partes", e o considerando 3, onde se refere que "Uma ação coletiva deve constituir um modo eficaz e eficiente de proteger os interesses coletivos dos consumidores. Deve permitir que as entidades qualificadas atuem a fim de garantir o cumprimento das disposições pertinentes da legislação da União e ajudem a superar os obstáculos que os consumidores enfrentam no âmbito de ações individuais, nomeadamente a incerteza em relação aos seus direitos e aos mecanismos processuais 
Este diploma legal define os casos e os termos em que são conferidos e podem ser exercidos o direito de participação popular em procedimentos administrativos e o direito de ação popular para a prevenção, a cessação ou a perseguição judicial das infrações previstas no n. ${ }^{\circ} 3$, do artigo 52. ${ }^{\circ}$, da CRP.

Destarte, o artigo 52.0, da CRP, refere-se, exemplificativamente ${ }^{10}$, às infrações contra a saúde pública, os direitos dos consumidores, a qualidade de vida e a preservação do ambiente e do património cultural.

A Lei n. ${ }^{\circ}$ 83/95, de 31 de agosto, apesar de remeter, no n. ${ }^{\circ} 1$, do artigo $1.0^{\circ}$, para o n. ${ }^{\circ} 3$, do artigo 52.0, da CRP, apresenta, no n. ${ }^{\circ} 2$, um elenco exemplificativo, no qual designa quais os interesses protegidos, a saber: a saúde pública, o ambiente, a qualidade de vida, a proteção do consumo de bens e serviços, o património cultural e o domínio público. E, apesar deste elenco não assumir um caráter taxativo, o certo é que resume aqueles que são os domínios em que a ação popular mais tem sido utilizada, quer no nosso ordenamento, quer em outros ordenamentos jurídicos.

\section{A titularidade DO DIREITO DE AÇÃo POPULAR E A LEGITIMIDADE ATIVA}

O Código de Processo Civil, no âmbito da legitimidade das partes, perfilhou a teoria segundo a qual o autor é parte legítima quando tem interesse em demandar ${ }^{11}$.

Não obstante, neste particular, a legitimidade não se traduz nesse interesse em demandar, mas antes no exercício do direito de ação popular consagrado na CRP e regulado pela Lei n. ${ }^{\circ} 83 / 95$, de 31 de agosto ${ }^{12}$, que, por sua vez, atribui a titularidade do direito procedimental de participação

disponíveis, as reticências psicológicas em avançar com um processo e o saldo negativo entre os custos e os benefícios esperados das ações individuais."

10 O elenco apresentado pelo n. ${ }^{\circ} 3$, do artigo 52.0, da CRP é precedido pelo termo «nomeadamente», à semelhança do que se verifica a respeito do artigo 1.0 , n.0 2, da Lei n. 0 83/95, de 31 de agosto, em que é utilizado o termo «designadamente». Vd. MONTEIRO, António Pedro Pinto; JÚDICE, José Miguel, "Class actions \& Arbitration in the European Union-Portugal", em Estudos em Homenagem a Galvão Teles, Coimbra, Almedina, 2012, pp.189-205, p.192; e "Study on the State of Collective Redress in the EU in the context of the implementation of the Commission Recommendation", da Comissão Europeia, 2017, disponível na internet emWWW: <URL:https://www.biicl.org/documents/1881_StudyontheStateofCollectiveRedr ess.pdf?showdocument $=1$, p. 236.

${ }^{11}$ Vd. AMARAL, Jorge Augusto Pais de, "Direito Processual Civil", 11.a edição, Coimbra, Almedina, 2014, pp.115 e ss., "Na redação anterior à reforma do Processo Civil que entro em vigor em 1997, não constava deste preceito a expressão: "tal como é configurada pelo autor. (...) Com esta alteração, o legislador quis pôr termo a uma questão muito antiga que tanta tinta fez correr, durante várias décadas (...). Na tese defendida por Barbosa de Magalhães, as partes eram legítimas, atendendo à relação controvertida tal como a configurava o autor. (...) Para Alberto dos Reis, o réu era parte ilegítima, por não ser o sujeito da relação material controvertida litigada (...). Desta forma, hoje raramente se poderá falar de ilegitimidade das partes. (...) O réu passará a ser absolvido do pedido em muitos casos em que, anteriormente, era absolvido da instância.

${ }^{12}$ Neste sentido, vd. AMARAL, Jorge Augusto Pais de, "Direito Processual Civil", op. cit., pp.128 e ss.. 
popular e do direito de ação popular (i) a qualquer cidadão no gozo dos seus direitos civis e políticos ${ }^{13}$; (ii) às associações e fundações defensoras dos interesses em causa $^{14}$; (iii) às autarquias locais, em relação aos interesses de que sejam titulares residentes na área da respetiva circunscrição ${ }^{15}$.

$\mathrm{Na}$ senda de Gomes CANOTILHO e Vital Moreira, estamos perante um alargamento da legitimidade processual ativa a todos os cidadãos, independentemente do seu interesse individual ou da sua relação específica com os bens ou interesses em causa ${ }^{16-17}$.

Pois, o artigo $2 .^{\circ}$ da referida lei, depois de elencar os cidadãos no gozo dos seus direitos civis e políticos e as associações e fundações defensoras dos interesses em causa como titulares dos direitos de participação procedimental e do direito de ação popular, refere, expressamente, que tal titularidade se verifica «independentemente de terem ou não interesse direto na demanda».

Neste sentido, o Código de Processo Civil também prevê, no capítulo II (legitimidade das partes), do título III (das partes), que têm legitimidade

${ }^{13}$ Vd. a este respeito, SOUSA, Miguel Teixeira de, "Legitimidade Processual (...)", op. cit., pp.422 e ss..

${ }^{14}$ Cf. CANOTILHO, J. J. Gomes; MOREIRA, Vital, "Constituição da República Portuguesa Anotada", op. cit., p.698, "A ação popular promovida por associações não se confunde com ação de grupo. Esta significa que é reconhecida legitimidade a uma associação para defender, por direito próprio, os interesses individuais normativamente protegidos dos seus associados («ação coletiva egoística») ou para proteger, sob determinados pressupostos, os interesses públicos resultantes da violação de preceitos jurídicos («ação coletiva altruística»). Para que uma ação coletiva promovida por associações adquira o caráter de ação popular será necessário que ela preencha os requisitos materiais e processuais definidos na lei quanto para este tipo de ação".

A este respeito, vd. ainda SOUSA, Miguel Teixeira de, "A Legitimidade Popular (...)", op. cit., p.27, onde se diz "A prossecução do fim estatutário da entidade coletiva não implica qualquer apropriação do interesse difuso que ela defende. (...) Aliás, apesar de várias razões poderem impor a representação de um interesse difuso por uma associação (...), deve ser combatida qualquer tentativa de essa entidade procurar confundir o seu interesse estatutário com o interesse difuso, pois que isso equivaleria a transformar a representação dos interessados numa apropriação daquele interesse."

${ }^{15}$ Cfr. ANDRADE, José Robin de, "A Acção Popular no Direito Administrativo Português", Coimbra, Coimbra Editora, 1967, p.3, "(...) o que caracteriza o instituto da ação popular éo facto de a legitimidade ser reconhecida e averiguada, não de um modo concreto e casuístico, mas em termos gerais e abstratos".

${ }^{16}$ Cf. CANOTILHO, J. J. Gomes; MOREIRA, Vital, "Constituição da República Portuguesa Anotada", op. cit., p.697.

17 Vd. SOUSA, Miguel Teixeira de, "Legitimidade Processual (...)", op. cit., p.413, "No seu sentido mais vulgarizado de interesses relativos a todos e a cada um dos membros de uma sociedade, os interesses difusos são expressão da complexidade das sociedades de capitalismo avançado (...) e, muito em particular, das relações de massas que nelas se estabelecem na produção e consumo de bens e no comércio jurídico. Um produto defeituoso de largo consumo é suscetível de prejudicar um grande número de consumidores, tal com um prospeto enganoso sobre a real situação de uma sociedade comercial cotada na bolsa pode implicar prejuízos avultados em muitos dos seus grandes e pequenos acionistas. Esses interesses difusos originam algumas dificuldades no plano da sua jurisdicionalização, isto é, nos aspetos relacionados com a sua defesa através dos tribunais. Mas, qualquer que sejam as dificuldades suscitadas, a necessidade da sua tutela judicial é certamente uma evidência $(. .) .$. 
para propor e intervir nas ações e procedimentos cautelares destinados, designadamente, à defesa da saúde pública, do ambiente, da qualidade de vida, do património cultural e do domínio público, bem como à proteção do consumo de bens e serviços, qualquer cidadão no gozo dos seus direitos civis e políticos, as associações e fundações defensoras dos interesses em causa, as autarquias locais e o Ministério Público.

Por sua vez, a Lei n. 0 83/95, de 31 de agosto, a respeito da legitimidade das partes ${ }^{18}$, no que concerne, concretamente, à legitimidade ativa das associações e fundações, exige o preenchimento de três requisitos ${ }^{19}$.

Em primeiro lugar, as associações e fundações devem ser dotadas de personalidade jurídica.

Nos termos do disposto nos artigos $158 .^{\circ}$ e $167 .^{\circ}$, ambos do Código Civil, as associações constituídas por escritura pública ou por outro meio legalmente admitido, que contenham as especificações relativas aos bens ou serviços com que os associados concorrem para o património social, à denominação, ao fim e sede da pessoa coletiva, à forma do seu funcionamento e duração (quando não se constitua por tempo indeterminada), gozam de personalidade jurídica.

Por sua vez, as fundações adquirem personalidade jurídica pelo reconhecimento, o qual é individual e da competência da autoridade administrativa ${ }^{20}$.

Em segundo lugar, estas associações e fundações devem incluir, expressamente, nas suas atribuições, ou nos seus objetivos estatutários, a defesa dos interesses que estejam em causa na respetiva ação.

Em terceiro e último lugar, é necessário que as associações e fundações não exerçam qualquer tipo de atividade profissional concorrente com empresas ou profissionais liberais.

Só quando estes requisitos se encontrem cumulativamente preenchidos é que as associações e fundações gozam de legitimidade ativa para intervirem na respetiva ação judicial ${ }^{21}$.

\section{O EXERCÍCIO DO DIREITO DE AÇÃO POPULAR}

Deve-se começar por salientar que a ação popular civil pode revestir qualquer uma das formas previstas no Código de Processo Civil, ou seja, pode ser uma ação declarativa ou uma ação executiva ${ }^{22}$.

\footnotetext{
18 Vd. OTERO, Paulo, "A Ação Popular: configuração e valor no atual Direito português, Revista da Ordem dos Advogados, ano 59, 1999, dezembro, Lisboa, pp.871-893, p.871, onde $O$ autor começa por afirmar que "A ação popular, sendo sempre uma ação judicial e, neste sentido, a expressão do direito fundamental de acesso aos tribunais, distinguese de todas as demais modalidades de ações pela amplitude dos critérios determinativos da legitimidade para a respetiva propositura."

${ }^{19}$ Neste sentido, vd. SOUSA, Miguel Teixeira de, "A Legitimidade Popular (...)", op. cit., pp.179 e ss..

20 Vd. HÖRSTER, Heinrich Ewald, "A parte geral do código civil português", 6.a reimpressão da edição de 1992, Coimbra, Almedina, 2011, pp.357 e ss..

${ }^{21}$ Cfr. artigo 3.0 da Lei n.0 83/95, de 31 de outubro.

${ }^{22}$ Vd. FREITAS, José Lebre de, "Introdução ao Processo Civil: conceito e princípios gerais à luz do novo código", 3. a edição, Coimbra, Coimbra Editora, 2013, pp.29 e ss..
} 
Por sua vez, sendo declarativa pode ser de simples apreciação (positiva ou negativa), de condenação ou constitutiva (constitutiva, modificativa ou extintiva).

Revestindo a forma de ação executiva, pode a ação popular civil ser uma ação executiva para pagamento de quantia certa, para entrega de coisa certa ou para prestação de um facto (positivo ou negativo) ${ }^{23}$.

O artigo 13.0, da Lei n. ${ }^{\circ}$ 83/95, de 31 de agosto, prevê um regime especial relativo ao indeferimento da petição inicial, de onde resulta a possibilidade de a petição inicial ser indeferida quando o julgador entenda que é manifestamente improvável a procedência do pedido, ouvido o Ministério Público e feitas, preliminarmente, as averiguações que o julgador tenha por justificadas, ou que o autor, ou o Ministério Público, requeiram.

De igual modo, este diploma legal consagra também um regime especial de representação processual, em que o autor representa por iniciativa própria, com dispensa de mandato ou autorização expressa ${ }^{24}$, todos os demais titulares dos direitos ou interesses em causa que não tenham exercido o direito de autoexclusão.

Com efeito, recebida a petição de ação popular, os titulares dos interesses em causa na ação, e não intervenientes nela, são citados ${ }^{25}$ para o efeito de, no prazo fixado pelo juiz, passarem a intervir no processo a título principal, querendo, aceitando-o na fase em que se encontrar, e para declararem nos autos se aceitam ou não ser representados pelo autor ou se, pelo contrário, se excluem dessa representação ${ }^{26}$, nomeadamente para o efeito de Ihes não serem aplicáveis as decisões proferidas.

Caso o titular do direito de ação nada diga, a sua passividade vale, no espírito da lei, como aceitação, muito embora o titular que não tenha

${ }^{23}$ Cf. AMARAL, Jorge Augusto Pais de, "Direito Processual Civil", op. cit., pp.27 e ss..

${ }^{24}$ Neste sentido, vd. ANTUNES, Henrique Sousa, "Class Actions, Group Litigation \& Other Forms of Collective Litigation", [Em linha], [Consult. 31 mai. 2018], disponível na internet

em WWW: <URL:http://globalclassactions.stanford.edu/sites/default/files/documents/Portuga I_National_Report.pdf, p.11.

${ }^{25}$ A citação, nos termos previstos no artigo $15 .{ }^{\circ}$, n.o 2, da Lei n.o 83/95, de 31 de agosto, será feita por anúncio ou anúncios tornados públicos através de qualquer meio de comunicação social ou editalmente, consoante estejam em causa interesses gerais ou geograficamente localizados, sem obrigatoriedade de identificação pessoal dos destinatários, que poderão ser referenciados enquanto titulares dos mencionados interesses, e por referência à ação de que se trate, à identificação de pelo menos o primeiro autor, quando seja um entre vários, do réu ou réus e por menção bastante do pedido e da causa de pedir. Quando não for possível individualizar os respetivos titulares, a citação far-se-á por referência ao respetivo universo, determinado a partir de circunstância ou qualidade que Ihes seja comum, da área geográfica em que residam ou do grupo ou comunidade que constituam, em qualquer caso sem vinculação à identificação constante da petição inicial.

${ }^{26}$ Vd. a este respeito a parte final, do n. ${ }^{\circ} 2$, do artigo $5 .{ }^{\circ}$ da Proposta de Diretiva, onde se refere que "Para requerer uma ação inibitória, a entidade qualificada não precisa de obter um mandato dos consumidores individuais interessados ou de fornecer prova das perdas ou danos efetivos por estes sofridos, nem de demonstrar a existência de dolo ou negligência pelo profissional em causa". 
procedido à sua exclusão no prazo definido pelo juiz possa, ainda, fazê-lo, mediante declaração expressa nos autos, até ao termo da produção de prova ou fase equivalente.

Com efeito, o nosso ordenamento jurídico optou pelo regime do opt-out, o que significa que os titulares dos direitos ou interesses em causa estão, automaticamente, vinculados à ação popular, que tenha por objeto a defesa de interesses individuais homogéneos daqueles titulares, ficando apenas excluídos no caso de declararem que essa não é a sua pretensão ${ }^{27}$.

Embora esta questão suscite, frequentemente, controvérsia no mundo jurídico, parece-nos que, preferencialmente, o regime aplicável à ação popular deve ser de opt-in, de modo a que figurem como sujeitos processuais e que sejam abrangidos pela respetiva decisão judicial apenas os titulares dos direitos ou interesses que tenham efetivamente interesse em participar e tenham demonstrado esse propósito.

\section{O PEDIDO NA AÇÃo COLETIVA}

Em vários Estados-Membros, as associações e fundações só podiam peticionar a cessação da conduta lesiva, mas já não a correspetiva indemnização pelos danos causados aos titulares do direito.

Ao invés, no direito português, prevê-se a possibilidade de peticionar a cessação da conduta lesiva bem como a indemnização ${ }^{28}$, já que o próprio preceito constitucional inclui "o direito de requerer para o lesado ou lesados a correspondente indemnização".

Deste modo, o autor popular prosseguirá para além do fim altruísta defesa de um interesse comum a uma pluralidade de pessoas - um fim egoísta - reparação do dano individualmente sofrido ${ }^{29}$.

Note-se, neste particular, que a Proposta de Diretiva estabelece ${ }^{30}$, a este respeito, que os Estados-Membros devem garantir que as associações e fundações podem intentar ações coletivas, com o propósito de obter (i) uma decisão inibitória proferida no âmbito de um procedimento cautelar, sempre que exista um fundado receio de que outrem cause lesão grave e dificilmente reparável ao seu direito ${ }^{31}$, ou (ii) uma decisão inibitória que

\footnotetext{
${ }^{27}$ Neste sentido, vd. REIS, Rafael Vale e, "Collective Redress and Health Care Law: The Specific Characteristics of Group Compensation under Portuguese Law", em Collective Redress in Europe: Why and How?, Ed. Eva Lein, Duncan Fairgrieve, Marta Otero Crespo e Vincent Smith, BIICL, 2015, p.390.

${ }^{28}$ Cfr. artigo 555. ${ }^{\circ}$ do Código de Processo Civil, "Pode o autor deduzir cumulativamente contra o mesmo réu, num só processo, vários pedidos que sejam compatíveis, se não se verificarem as circunstâncias que impedem a coligação." Vd. ainda LEBRE DE FREITAS, José; ALEXANDRE, Isabel, "Código de Processo Civil: Anotado", Vol. 2.0, 3.a edição, Coimbra, Almedina, 2018, p. 503 e ss., "a dedução cumulativa de pedidos exige que eles sejam substancialmente compatíveis (...)".

29 Neste sentido, MIRANDA, Jorge; MEDEIROS, Rui, "Constituição Portuguesa Anotada", op. cit., p.1030.

${ }^{30}$ Cfr. artigo $5 .{ }^{\circ}$ da Proposta de Diretiva.

${ }^{31}$ Cfr. artigo $362 .{ }^{\circ}$, n. ${ }^{\circ} 1$, do Código de Processo Civil. A este respeito, vd. VALLES, Edgar, "Prática Processual Civil com o Novo CPC", 9. a edição, Coimbra, Almedina, 2015, p.277, "As [providências] conservatórias visam prevenir a ocorrência ou a continuação de
} 
reconheça que a prática em causa constitui uma infração e, se for caso disso, ponha termo a essa prática ou a proíba.

Todavia, a Proposta de Diretiva não se limita a estabelecer a possibilidade de os Estados-Membros garantirem às associações ou fundações a faculdade de recorrer à via judicial com vista a colocar termo a determinada conduta. Com efeito, prevê-se, ainda, no n.o 3, do artigo 5.0, que estas entidades devem poder peticionar, para além da proibição da conduta $^{32}$, as "medidas destinadas a eliminar os efeitos persistentes da infração", i.e., a correspondente indemnização.

\section{A RESPONSABILIDADE CIVIL OBJETIVA E A RESPONSABILIDADE CIVIL SUBJETIVA}

A responsabilidade por violação dolosa ou culposa dos interesses do titular constitui o agente causador no dever de indemnizar o lesado ou lesados pelos danos causados ${ }^{33}$.

Esta indemnização devida ao(s) titular(es) dos interesses ou direitos é fixada globalmente, nos termos gerais da responsabilidade civil, previstos no Código Civil $^{34}$.

O direito à indemnização prescreve no prazo de três anos a contar do trânsito em julgado da sentença que o tiver reconhecido.

Todavia, os montantes correspondentes a direitos prescritos serão entregues ao Ministério da Justiça, que os escriturará em conta especial e os afetará ao pagamento da procuradoria, nos termos do artigo 21.0 , da Lei n.o 83/95, de 31 de agosto, e ao apoio no acesso ao direito e aos tribunais de titulares de direito de ação popular que justificadamente o requeiram.

Por sua vez, existe, ainda, a obrigação de indemnização por danos, independentemente de culpa, sempre que de ações ou omissões do agente tenha resultado ofensa de direitos ou interesses protegidos nos termos da Lei n.o 83/95, de 31 de agosto, e no âmbito ou na sequência de uma atividade objetivamente perigosa.

Este regime é semelhante ao previsto no Código Civil, relativamente à responsabilidade civil objetiva, característica de atividades objetivamente perigosas.

Por fim, deve-se notar que a própria Lei n.o 83/95, de 31 de agosto, estatui que sempre que o exercício de uma atividade envolva risco anormal para os interesses protegidos pela presente lei, deverá ser

produção de danos graves e irreparáveis ou de difícil reparação no direito do seu titular, acautelando o efeito útil do reconhecimento definitivo desse direito. As antecipatórias são aquelas que, face à situação de urgência que Ihes está associada, antecipam os efeitos jurídicos próprios da decisão que vier a ser proferida na ação principal, assim como a realização do direito."

32 Assim resulta do n.o 4, do artigo 5.0, da Proposta de Diretiva, quando o legislador refere "os Estados-Membros devem assegurar que as entidades qualificadas podem requerer, numa única ação coletiva (...)".

33 A este respeito, vd. MOTA PINTO, Carlos, "Interesse Contratual Negativo e Interesse Contratual Positivo", Vol. I e Vol. II, Coimbra, Coimbra Editora, 2009.

34 Vd., a respeito da finalidade reparatória e particularmente dos danos de massa, SOUSA, Miguel Teixeira de, "A Legitimidade Popular (...)", op. cit., pp.153 e ss.. 
exigido ao respetivo agente seguro da correspondente responsabilidade civil como condição do início ou da continuação daquele exercício.

\section{A DECISÃo JUDICIAL dA AÇÃO COLETIVA E OS SEUS EFEITOS}

Salvo quando julgadas improcedentes por insuficiência de provas ou quando o julgador deva decidir por forma diversa, por motivações próprias do caso concreto, os efeitos das sentenças transitadas em julgado proferidas no âmbito de processo que tenham por objeto a defesa de interesses individuais homogéneos abrangem os titulares dos direitos ou interesses que não tiverem exercido o direito de autoexclusão da representação ${ }^{35}$.

Conforme assinalamos supra, o nosso regime é de opt-out, o que pode colocar em causa o princípio da tutela jurisdicional efetiva, conforme se constatou no célebre acórdão do Tribunal de Justiça da União Europeia (TJUE), que envolveu o Supremo Tribunal Espanhol, e que justificou a alteração de regime, tendo a ação coletiva deixado de fazer caso julgado para todos (os que estão dentro e fora), e passado apenas a abranger aqueles que participam da ação.

Por esta razão, atendendo aos interesses e direitos em causa, concordamos que o melhor regime é, efetivamente, o de opt-in.

Após o trânsito em julgado das decisões judiciais, as mesmas são publicadas, a expensas da parte vencida e sob pena de desobediência, com menção do trânsito em julgado, em dois dos jornais presumivelmente lidos pelo universo dos interessados no seu conhecimento, à escolha do juiz da causa, que poderá determinar que a publicação se faça por extrato dos seus aspetos essenciais, quando a sua extensão desaconselhar a publicação por inteiro.

O diploma legal em apreço prevê que pelo exercício do direito de ação popular não são exigíveis preparos, e que o autor fica isento do pagamento de custas em caso de procedência parcial do pedido. Todavia, em caso de decaimento total, o autor interveniente será condenado em montante a fixar pelo juiz, entre um décimo e metade das custas que, normalmente, seriam devidas, tendo em conta a sua situação económica e a razão formal ou substantiva da improcedência.

Note-se que a responsabilidade por custas dos autores intervenientes é solidária, nos termos gerais.

Deve-se, ainda, referir que, no domínio da ação popular, são aplicáveis as regras de processo civil que não se mostrem incompatíveis com a disciplina da ação coletiva, como é o caso do referido instituto da litigância de má-fé, previsto e regulado pelos artigos $542 .^{\circ}$ e seguintes.

${ }^{35}$ Cfr. artigo 16. ${ }^{\circ}$, da Lei n. ${ }^{\circ}$ 83/95, de 31 de agosto. 


\section{A RECOMENDAÇÃO DA COMISSÃO 2013/396/UE, DE 11 DE JUNHO DE 2013 E A PROPOSTA DE DIRETIVA DO PARLAMENTO EUROPEU E DO CONSELHO RELATIVA A AÇÕES COLETIVAS PARA PROTEGER OS INTERESSES COLETIVOS DOS CONSUMIDORES E QUE REVOGA A DIRETIVA 2009/22/CE}

A recomendação enquanto fonte de direito assume um caráter de soft law, pelo que não é juridicamente vinculante para os Estados-Membros. Todavia, contém as linhas orientadoras comuns, no que respeita aos princípios que devem reger os mecanismos de tutela coletiva inibitórios e indemnizatórios dos Estados-Membros aplicáveis às violações de direitos garantidos pelo direito da União ${ }^{36}$.

O desiderato desta recomendação é precisamente facilitar o acesso à justiça, impedir práticas ilícitas e permitir que as partes lesadas obtenham uma reparação em situações de dano em massa ${ }^{37}$, resultante de violações de direitos concedidos pelo direito da União Europeia, prescrevendo salvaguardas processuais adequadas a evitar a litigância abusiva.

Como tal, recomenda-se que todos os Estados-Membros disponham de mecanismos de tutela coletiva a nível nacional, tanto inibitórios como indemnizatórios.

Conforme referimos supra, o ordenamento jurídico português prevê, precisamente, que o direito de ação popular possa abranger quer o pedido de cessação da conduta, quer o pedido indemnizatório. O mesmo não se verifica relativamente a outros Estados-Membros.

Para além disso, recomenda-se, ainda, que os processos de tutela coletiva sejam justos, equitativos, tempestivos e não sejam proibitivamente onerosos.

No que respeita concretamente à legitimidade para intentar uma ação representativa ${ }^{38}$, a Recomendação estatui que os Estados-Membros devem designar as entidades representativas para intentar ações representativas com base em condições claramente definidas.

Como tal, apresenta as condições mínimas a observar para o efeito, a saber:

a) A entidade não deve ter fins lucrativos;

\footnotetext{
${ }^{36}$ Vd. OTERO CRESPO, Marta, "Las acciones colectivas en Europa: ¿Un paso adelante?: Las líneas generales propuestas en la Recome ndación de la Comisión Europea sobre los principios comunes aplicables a los mecanismos de recurso colectivo de cesación o de indemnización en los Estados miembros en caso de violación de los derechos reconocidos por el Derecho de la Unión (2013/ 396/ UE)", Boletín Centro de Estudos e Documentación Europeos, Universidade de Santiago de Compostela, nov.2013.

37 Nos termos e para efeitos da Recomendação considera-se situação de dano em massa uma situação em que duas ou mais pessoas singulares ou coletivas alegam terem sofrido danos que causem prejuízos resultantes da mesma atividade ilegal de uma ou mais pessoas singulares ou coletivas.

38 Deve-se notar que nos termos e para os efeitos da Recomendação entende-se por ação representativa uma ação intentada por uma entidade representativa, uma entidade certificada ad hoc ou uma autoridade pública em nome e por conta de duas ou mais pessoas, singulares ou coletivas, que alegam estarem expostas ao risco de sofrerem danos ou que tenham sido lesadas numa situação de dano em massa, não sendo essas pessoas partes no processo.
} 
b) Deve existir uma relação direta entre os objetivos principais da entidade e os direitos concedidos pelo direito da União que se alega terem sido violados e em relação aos quais é intentada a ação;

c) A entidade deve dispor de capacidade suficiente em termos de recursos financeiros e humanos, e de conhecimentos jurídicos, para representar vários requerentes agindo da melhor forma no interesse destes.

Os requisitos ora elencados não correspondem, na íntegra, aos pressupostos internos da legitimidade ativa das associações ou fundações que prossigam o fim de defesa dos interesses dos titulares do direito afetado. Não obstante, é possível identificar alguns pontos comuns entre um e outro diploma.

Por sua vez, no que concerne à informação dos titulares sobre a existência de uma ação representativa, recomenda-se que os Estados-Membros assegurarem que a entidade representativa ou o grupo de requerentes pode divulgar informações sobre uma alegada violação de direitos concedidos pelo direito da União e a sua intenção de pedir uma medida inibitória que Ihe ponha termo, assim como sobre uma situação de dano em massa e a sua intenção de propor uma ação de indemnização sob a forma de tutela coletiva.

Sendo certo que o mesmo raciocínio se aplica quanto às ações compensatórias que, neste sentido, devem garantir as mesmas possibilidades de informação sobre as ações compensatórias em curso à entidade representativa, à entidade certificada ad hoc, a uma autoridade pública ou a um grupo de requerentes.

Com efeito, os métodos de divulgação devem ter em conta as circunstâncias específicas de cada situação de dano em massa, a liberdade de expressão, o direito à informação e o direito à proteção da reputação ou do valor da empresa de um requerido antes de a sua responsabilidade pela violação ou pelo dano alegados ser determinada pela decisão final do tribunal.

Relativamente à matéria das custas processuais, uma vez mais, não resultam da recomendação novidades, já que conforme se refere no próprio texto, vale, aqui, o «princípio do perdedor pagador», ou seja, precisamente o mesmo princípio que a Lei n. ${ }^{\circ} 83 / 95$, de 31 de agosto, prevê a respeito da ação coletiva e o que consta atualmente do Código de Processo Civil português.

Mas, já no que diz respeito ao método de financiamento da ação judicial, a recomendação consagrou uma disciplina algo interessante.

$\mathrm{Na}$ recomendação refere-se que a parte requerente deve declarar ao tribunal no início do processo a origem dos fundos utilizados para financiar a ação judicial.

Ademais, estabelece-se que o tribunal deve ser autorizado a suspender a instância, no caso de utilização de recursos financeiros proporcionados por um terceiro, nos seguintes casos:

a) Quando exista um conflito de interesses entre o terceiro, por um lado, e o requerente e seus membros, por outro; 
b) Quando o terceiro não dispuser de recursos suficientes para cumprir os seus compromissos financeiros para com a parte requerente que intenta a ação de tutela coletiva;

c) Quando o requerente não disponha de recursos suficientes para satisfazer as custas da parte adversa, caso seja vencido na ação de tutela coletiva.

Foi precisamente neste contexto que surgiram os third-party funding ${ }^{39}$.

Este modelo de negócio de financiamento de litígios por terceiros, baseado no empréstimo, por fundos de investimento, do montante financeiro necessário para assegurar o pagamento de todas as despesas relacionadas com a ação judicial, pressupõe, no final, um pagamento do serviço prestado.

Os third-party funding ainda não chegaram ao nosso ordenamento jurídico, mas têm proliferado por vários Estados-Membros da União.

A recomendação referia-se já à existência destes fundos de investimento e incluiu-os no seu próprio texto.

Todavia, esta nova figura tem suscitado acesos debates no mundo jurídico, onde se discute essencialmente as seguintes questões: saber se se trata de uma atividade de financiamento sujeita a licenciamento pelas autoridades supervisoras da atividade bancária e financeira; saber se se trata de uma modalidade de quota litis ou de partilha de honorários; saber qual o enquadramento da questão atinente ao sigilo profissional; saber em que medida se trata de um negócio usurário; e, finalmente, saber em que medida uma ação (um litígio) pode ser o objeto de um negócio ${ }^{40}$.

Por seu turno, a Proposta de Diretiva do Parlamento Europeu e do Conselho relativa a ações coletivas para proteger os interesses coletivos dos consumidores e que (atualiza e) revoga a diretiva 2009/22/CE ${ }^{41}$ surge no panorama das ações inibitórias em matéria de proteção dos interesses dos consumidores.

Tal como assinalado supra, esta proposta de diretiva insere-se no âmbito do «New Deal for Consumers», previsto no Programa de Trabalho da Comissão para 2018, por forma a melhorar a eficácia do processo de ação inibitória e contribuir para eliminar as consequências das infrações ao direito da União que afetam os interesses coletivos dos consumidores. Da proposta identificam-se quatro objetivos principais: (i) alargamento do âmbito de aplicação (ii) definição dos critérios legais de que depende a representação em juízo dos consumidores, pelas entidades qualificadas, e o financiamento por terceiros; (iii) eficiência do processo

\footnotetext{
${ }^{39}$ Vd. HENRIQUES, Duarte Gorjão, "Third Party Funding" ou o Financiamento de Litígios por Terceiros em Portugal", Revista Ordem dos Advogados [Em linha], [Consult. 31 mai. 2018], disponível na internet em WWW:<URL:http://bch.pt/ROA\%20III_IV\%202015.pdf, pp. 573-624.

${ }^{40}$ Cfr. Vd. HENRIQUES, Duarte Gorjão, "Third Party Funding" ou o Financiamento de Litígios por Terceiros em Portugal", op. cit., pp.613 e ss..

41 A Proposta de Diretiva tem em consideração a Recomendação da Comissão 2013/396/UE, de 11 de junho de 2013, sobre os princípios comuns que devem reger os mecanismos de tutela coletiva inibitórios e indemnizatórios dos Estados-Membros aplicáveis às violações de direitos garantidos pelo direito da União.
} 
(maior brevidade e menor onerosidade processual); e (iv) reparação inibitória e indemnizatória.

No que respeita ao âmbito de aplicação, devemos atender ao conteúdo do anexo I da Diretiva, de onde constam os atos legislativos da União, no âmbito dos quais as entidades competentes poderão intentar ações coletivas, quando estes sejam violados por profissionais e lesem ou sejam suscetíveis de lesar os interesses coletivos dos consumidores.

Por seu turno, para que uma entidade possa ser considerada qualificada, é necessário o preenchimentos dos seguintes requisitos:

a) A sua constituição deve respeitar os critérios legais definidos pelo respetivo Estado-Membro;

b) Deve ter um interesse legítimo em garantir o cumprimento da legislação da União abrangida pela diretiva; e

c) Não deve prosseguir fins lucrativos.

Ademais, a Proposta de Diretiva aponta, ainda, como eixo principal a eficiência do processo que, como supra referimos, se traduz numa maior celeridade processual e numa menor onerosidade. Assim, os EstadosMembros devem adotar as medidas necessárias a garantir que as ações coletivas previstas sejam tratadas com a devida celeridade, nomeadamente quando estejam em causa um procedimento cautelar.

Por fim, no que diz respeito à reparação inibitória e indemnizatória, e tal como referido supra, os Estados-Membros devem permitir às entidades qualificadas o acesso à ação judicial comum, bem como ao procedimento cautelar, conforme o que se afigurar necessário, in casu, para tutelar os interesses dos consumidores.

Note-se a este respeito que a Proposta de Diretiva estabelece que para requerer uma ação inibitória, a entidade qualificada não precisa de obter um mandato dos consumidores individuais interessados ou de fornecer prova das perdas ou danos efetivos por estes sofridos, nem de demonstrar a existência de dolo ou negligência pelo profissional em causa.

\section{A AÇÃo COLETIVA NO ÂMBITO DO REgULAMENTO GERAL SOBRA A PROTEÇÃO DE DADOS}

O famigerado Regulamento Geral sobre a Proteção de Dados (RGPD) Regulamento (UE) 2016/679 do Parlamento Europeu e do Conselho, de 27 de abril de 2016 - que começa por afirmar, no considerando primeiro, que a proteção das pessoas singulares relativamente ao tratamento de dados pessoais é um direito fundamental, não se esqueceu de tratar o regime da ação coletiva.

Com efeito, no artigo $79.0^{\circ}$ do referido regulamento, reconhece-se o direito do titular dos dados à ação judicial contra um responsável pelo tratamento ou um subcontratado.

Nos termos deste preceito legal, sempre que o titular dos dados considere ter havido uma violação dos direitos que Ihe assistem nos termos da lei, na sequência do tratamento dos seus dados pessoais efetuado em 
violação do regulamento, este pode recorrer à via judicial, tendo em vista a tutela dos seus interesses legítimos ${ }^{42}$.

Conforme temos vindo a assinalar, o direito de ação popular reveste particular importância, especialmente por se tratar de um direito constitucionalmente consagrado.

Todavia, este direito que apelidamos de "constitucionalmente consagrado" não é, tal como também se referiu supra, um direito exclusivo do sistema português. Nota clara disso é, precisamente, a proposta de diretiva que tem vindo a ser trabalhada e que pretende alcançar, no seio da União Europeia, um regime uniforme e harmonizador no que respeita ao direito de ação popular, pois na sociedade moderna este regime jurídico tem-se revelado, acentuadamente, eficaz e imprescindível para a tutela dos interesses dos cidadãos.

Nesta senda, o RGPD consagrou, no artigo 80.0, sob a epígrafe «representação dos titulares dos dados» o direito de ação popular ${ }^{43}$.

O titular dos dados tem, assim, o direito de mandatar um organismo, organização ou associação sem fins lucrativos ${ }^{44}$, cujos objetivos sejam do interesse público e cuja atividade abranja a defesa dos direitos e liberdades do titular dos dados no que respeita à proteção dos seus dados pessoais, para, em seu nome, apresentar reclamação, exercer os seus direitos de reclamação a uma autoridade de controlo, de agir judicialmente contra uma autoridade de controlo, de agir judicialmente contra um representante pelo tratamento ou subcontratado e, ainda, exercer o direito de receber uma indemnização ${ }^{45}$, se tal estiver previsto no direito do Estado-Membro ${ }^{46}$.

Deve-se assinalar que o RGPD previu a possibilidade de o organismo, a organização ou a associação sem fins lucrativos, exercer, em nome do titular dos dados, o direito de receber uma indemnização, se tal estiver previsto no direito do Estado-Membro, tal como já sucede no direito

\footnotetext{
42 Note-se todavia que o recurso à via judicial não prejudica o recurso a qualquer outro meio, administrativo ou extrajudicial, de tutela dos direitos do titular dos dados, conforme se refere no n. ${ }^{\circ} 1$, do citado artigo 79.0 , do RGPD.

${ }^{43}$ Cfr. considerando 142, do RGPD.

44 Este organismo, organização ou associação sem fins lucrativos deve encontrar-se devida e legalmente constituído(a) ao abrigo da legislação de cada Estado-Membro.

${ }^{45} \mathrm{Vd}$. Artigo $82 .{ }^{\circ}$ do RGPD. Neste contexto, o conceito de dano deve ser interpretado em sentido lato, à luz da jurisprudência do Tribunal de Justiça, de uma forma que reflita plenamente os objetivos do RGPD, sendo certo que tal não prejudica os pedidos de indemnização por danos provocados pela violação de outras regras do direito da União ou dos Estados-Membros - Cfr. considerando 146, do RGPD.

${ }^{46}$ Deve-se assinalar uma vez mais que não existe uma estrita correspondência entre os requisitos legais de que depende a legitimidade ativa destas entidades representantes dos titulares dos cidadãos. No que concerne ao RGPD, afigura-se possível a representação dos titulares dos dados por um organismo, organização ou associação sem fins lucrativos, sendo certo que em relação a estas entidades, deve-se verificar o preenchimento dos seguintes requisitos: (i) constituição ao abrigo do direito de um Estado-Membro; (ii) os objetivos estatutários sejam do interesse público; (iii) a atividade prosseguida abranja a defesa dos direitos e liberdades do titular dos dados no que respeita à proteção de dados pessoais.
} 
português, mas ao contrário do que se verifica em tantos outros ordenamentos jurídicos.

Todavia, através da introdução da condição "se tal estiver previsto no direito do Estado-Membro", pode dar-se a situação de esse organismo, organização ou associação não estar autorizado(a) a pedir uma indemnização em nome do titular dos dados, independentemente do mandato que lhe é conferido por este.

Ademais, o legislador europeu concedeu aos Estados-Membros a prerrogativa de preverem que o organismo, a organização ou a associação sem fins lucrativos, independentemente de um mandato conferido pelo titular do dos dados, tenha nesse Estado-Membro direito a apresentar uma reclamação à autoridade de controlo competente e a exercer os direitos de agir judicialmente contra uma autoridade de controlo e; de agir judicialmente contra um representante pelo tratamento ou subcontratado; caso considerem que os direitos dos titulares dos dados, nos termos do regulamento, foram violados em virtude do tratamento ${ }^{47}$.

Conforme descortinamos anteriormente, podemos estar, nestes casos, perante um verdadeiro alargamento da legitimidade processual.

Note-se, uma vez mais, que o legislador foca a questão do mandato conferido pelos titulares dos dados pessoais, concedendo, tal como referido, aos Estados-Membros, a prerrogativa de regularem internamente esta questão.

Atendendo ao quadro legal vigente, entendemos que o regime atual da ação coletiva é aplicável no domínio da proteção de dados pessoais, não obstante as referências efetuadas a respeito da legitimidade ativa das entidades representativas dos titulares dos dados pessoais. Não se vislumbram razões que conduzam ao tratamento diferenciado (e menos favorável para o titular dos dados) da ação coletiva, no âmbito da proteção de dados pessoais, em relação àquele que é o regime geral previsto na lei portuguesa ${ }^{48}$.

Neste sentido, e de acordo com o disposto no artigo $14 .{ }^{\circ}$, da Lei n.o 83/95, de 31 de agosto, estes organismos, organizações ou associações de representação dos titulares dos dados estarão legitimados a representar por iniciativa própria, com dispensa de mandato ou autorização expressa, todos os titulares dos direitos ou interesses em causa que não exerçam, nos termos da lei, o direito de autoexclusão ${ }^{49}$.

\footnotetext{
${ }^{47}$ A este respeito vd. supra nota 14.

${ }^{48}$ Em sentido contrário, vd. COELHO, Cristina Pimenta, pp.630 e 631, "a não ser que o Estado português venha a admitir expressamente tal possibilidade, será necessário que os titulares dos dados confiram poderes de representação para que uma associação representativa dos direitos dos titulares de dados pessoais possa agir em seu nome".

${ }^{49}$ A título de exemplo da aplicação do regime da ação coletiva, previsto na Lei n.0 83/95, de 31 de agosto, no âmbito da proteção de dados pessoais, pense-se na ação coletiva interposta pela Associação Portuguesa para a Defesa do Consumidor - DECO, pessoa coletiva de utilidade pública, contra a Facebook, na sequência do incidente que envolveu a consultora britânica Cambridge Analytica. Através desta ação judicial, os cidadãos portugueses com conta naquela rede social terão a possibilidade de ser indemnizados pelo uso indevido dos seus dados, sem que para o efeito tenham constituído,
} 
Por fim, mas não menos importante, uma nota relativa à competência. Nos termos do RGPD, as ações intentadas contra o responsável pelo tratamento ou o subcontratado devem ser intentadas pelo requerente nos tribunais do Estado-Membro em que está estabelecido o responsável pelo tratamento ou o subcontratado, ou nos tribunais do Estado-Membro da residência do titular dos dados (exceto se o responsável pelo tratamento for uma autoridade de um Estado-Membro no exercício dos seus poderes públicos $)^{50}$.

\section{CONCLUSÃO}

I) A CRP consagra, no artigo 52. ${ }^{\circ}$ o direito de petição e direito de ação popular. Nos termos deste preceito, todos os cidadãos, pessoalmente ou através de associações de defesa dos interesses em causa, têm o direito de ação popular, nos casos e termos previstos na lei, incluindo o direito de requerer para o lesado ou lesados a correspondente indemnização.

II) O direito de ação popular é concretizado, no nosso ordenamento jurídico, pela legislação ordinária, nomeadamente pela Lei n. ${ }^{\circ}$ 83/95, de 31 de agosto.

III)A par da regulamentação interna, tem-se discutido no contexto da União Europeia a afirmação deste direito de ação coletiva, nomeadamente através da Recomendação da Comissão 2013/396/UE, de 11 de junho de 2013, e do «New Deal for Consumers», de 11 de abril de 2018.

O «New Deal for Consumers», de 11 de abril de 2018 é composto por duas propostas de diretivas: (i) uma proposta de alteração da Diretiva do Conselho relativa às cláusulas abusivas nos contratos celebrados com os consumidores, da Diretiva em matéria de indicações dos preços dos produtos oferecidos aos consumidores, da Diretiva relativa às práticas comerciais desleais entre empresas e consumidores e da Diretiva relativa aos direitos dos consumidores; (ii) uma proposta sobre ações representativas para a proteção dos interesses coletivos dos consumidores e que revoga a Diretiva 2009/22/CE, relativa às ações inibitórias.

IV) A legitimidade na ação popular é atribuída a todos os cidadãos no gozo dos seus direitos civis e político, às associações e fundações defensoras dos interesses em causa, e, ainda, às autarquias locais, em relação aos

previamente, mandato a favor desta associação, mas sem prejuízo do respetivo direito de autoexclusão previsto na lei.

50 Conforme se assinala no considerando 147, do RGPD, quando o regulamento previr regras específicas relativas à competência, nomeadamente no que diz respeito à interposição de recurso judicial, incluindo os pedidos de indemnização contra um responsável pelo tratamento ou um subcontratado, a aplicação de tais regras não deverá ser prejudicada por regras de competência gerais como as previstas no Regulamento (UE) n. ${ }^{\circ} 1215 / 2012$ do Parlamento Europeu e do Conselho, relativo à competência judiciária, ao reconhecimento e à execução de decisões em matéria civil e comercial. Significa isto que as regras específicas de competência internacional que venham a ser definidas pelo RGPD prevalecem sobre as demais regras de competência internacional gerais, não estivéssemos nós perante uma matéria consideravelmente sensível para a esfera jurídica dos titulares de dados, que nesta relação jurídica tenderão a ser a parte mais débil e que, por essa razão, precisam de uma maior tutela. 
interesses de que sejam titulares residentes na área da respetiva circunscrição.

A Lei n.o 83/95, de 31 de agosto, estabelece três requisitos de que depende a legitimidade ativa das associações e fundações: (i) as associações e fundações devem ser dotadas de personalidade jurídica; (ii) devem incluir, expressamente, nas suas atribuições, ou nos seus objetivos estatutários, a defesa dos interesses que estejam em causa na respetiva ação; e (iii) não devem exercer qualquer tipo de atividade profissional concorrente com empresas ou profissionais liberais.

V) A ação popular civil pode revestir qualquer uma das formas previstas no Código de Processo Civil.

O autor, na ação popular, representa, por iniciativa própria, com dispensa de mandato ou autorização expressa, todos os demais titulares dos direitos ou interesses em causa que não tenham exercido o direito de autoexclusão. Caso o titular do direito de ação nada diga, a sua passividade vale, no espírito da lei, como aceitação (regime do opt-out), o que significa que os titulares dos direitos ou interesses em causa estão, automaticamente, vinculados à ação popular.

VI) Os efeitos das sentenças transitadas em julgado, proferidas no âmbito de processo que tenham por objeto a defesa de interesses individuais homogéneos abrangem os titulares dos direitos ou interesses que não tiverem exercido o direito de autoexclusão da representação.

VII) O autor popular prosseguirá para além de um fim altruísta - defesa de um interesse comum a uma pluralidade de pessoas - um fim egoísta reparação do dano individualmente sofrido.

VIII) A responsabilidade por violação dolosa ou culposa dos interesses do titular constitui o agente causador no dever de indemnizar, nos termos do instituto jurídico da responsabilidade civil, previsto no Código Civil, o lesado ou lesados pelos danos causados.

A Lei n.o 83/95, de 31 de agosto, estatui igualmente o instituto da responsabilidade civil objetiva, isto é, a obrigação de indemnização por danos, independentemente de culpa, sempre que de ações ou omissões do agente tenha resultado ofensa de direitos ou interesses do titular, e no âmbito ou na sequência de uma atividade objetivamente perigosa.

IX) A Recomendação da Comissão 2013/396/UE, de 11 de junho de 2013 estabeleceu as linhas orientadoras comuns, no que respeita aos princípios que devem reger os mecanismos de tutela coletiva inibitórios e indemnizatórios dos Estados-Membros aplicáveis às violações de direitos garantidos pelo direito da União.

A recomendação consagrou, no que diz respeito ao método de financiamento da ação judicial, a figura do third-party funding. Este novo instituto, embora não exista (ainda?) no nosso ordenamento jurídico, figura em vários Estados-Membros da União e tem suscitado acesos debates no mundo jurídico, onde se discute essencialmente as seguintes questões: saber se se trata de uma atividade de financiamento sujeita a licenciamento pelas autoridades supervisoras da atividade bancária e financeira; saber se se trata de uma modalidade de quota litis ou de partilha de honorários; saber qual o enquadramento da questão atinente 
ao sigilo profissional; saber em que medida se trata de um negócio usurário; e, finalmente, saber em que medida uma ação (um litígio) pode ser o objeto de um negócio.

A Proposta de Diretiva do Parlamento Europeu e do Conselho relativa a ações coletivas para proteger os interesses coletivos dos consumidores e que (atualiza e) revoga a diretiva 2009/22/CE assenta em quatro eixos principais: (i) alargamento do âmbito de aplicação (ii) definição dos critérios legais de que depende a representação em juízo dos consumidores, pelas entidades qualificadas, e 0 financiamento por terceiros; (iii) eficiência do processo (maior brevidade e menor onerosidade processual); e (iv) reparação inibitória e indemnizatória.

X) O Regulamento Geral sobre a Proteção de Dados consagrou, no artigo $80 .{ }^{\circ}$, sob a epígrafe «representação dos titulares dos dados» o direito de ação popular.

O titular dos dados tem o direito de mandatar um organismo, organização ou associação sem fins lucrativos, cujos objetivos sejam do interesse público e cuja atividade abranja a defesa dos direitos e liberdades do titular dos dados no que respeita à proteção dos seus dados pessoais, para, em seu nome, apresentar reclamação, exercer os seus direitos de reclamação a uma autoridade de controlo, de agir judicialmente contra uma autoridade de controlo, de agir judicialmente contra um representante pelo tratamento ou subcontratado e, ainda, exercer 0 direito de receber uma indemnização, se tal estiver previsto no direito do Estado-Membro.

XI) O legislador europeu concedeu aos Estados-Membros a prerrogativa de preverem que o organismo, a organização ou a associação sem fins lucrativos, independentemente de um mandato conferido pelo titular do dos dados, tenha nesse Estado-Membro direito a apresentar uma reclamação à autoridade de controlo competente e a exercer os direitos de agir judicialmente contra uma autoridade de controlo e; de agir judicialmente contra um representante pelo tratamento ou subcontratado; caso considerem que os direitos dos titulares dos dados, nos termos do regulamento, foram violados em virtude do tratamento.

XII) O Regulamento Geral sobre a Proteção de Dados previu a possibilidade de o organismo, a organização ou a associação sem fins lucrativos, exercer, em nome do titular dos dados, o direito de receber uma indemnização, se tal estiver previsto no direito do Estado-Membro.

\section{BIBLIOGRAFIA}

ALVES, João, "Ação popular: manifesta improcedência do pedido - parecer do Ministério Público", Revista do Ministério Público 148, out-dez 2016, pp.141-149;

AMARAL, Jorge Augusto Pais de, "Direito Processual Civil", 11. a edição, Coimbra, Almedina, 2014;

AMARAL, Maria Lúcia, "A Forma da República", Coimbra, Coimbra Editora, 2012;

ANDRADE, José Carlos Vieira de, "Os Direitos Fundamentais na Constituição de 1976", 5. a edição, Coimbra, Almedina, 2012; 
ANDRADE, José Robin de, "A Acção Popular no Direito Administrativo Português", Coimbra, Coimbra Editora, 1967;

ANDRADE, Manuel A. Domingues, "Noções Elementares de Processo Civil", Coimbra, Coimbra Editora, 1993;

ANTUNES, Henrique Sousa, "Class Actions, Group Litigation \& Other Forms of Collective Litigation", [Em linha], [Consult. 31 mai. 2018], disponível na internet em WWW : <URL:http://globalclassactions.stanford.edu/sites/default/file s/documents/Portugal_National_Report.pdf;

ANTUNES, Nuno Sérgio Marques, "O Direito de Ação Popular no Contencioso Administrativo Português, Lisboa, Lex, 1997;

CANOTILHO, J. J. Gomes; MOREIRA, Vital, "Constituição da República Portuguesa Anotada", Vol. I, 4. a edição, Coimbra, Coimbra Editora, 2007;

FREITAS, José Lebre de, "Introdução ao Processo Civil: conceito e princípios gerais à luz do novo código", 3.a edição, Coimbra, Coimbra Editora, 2013;

GOUVEIA, Jorge Bacelar, "Manual de Direito Constitucional", Vol. I, 4.a edição, Coimbra, Almedina, 2014;

HENRIQUES, Duarte Gorjão, "Third Party Funding" ou o Financiamento de Litígios por Terceiros em Portugal", Revista Ordem dos Advogados [Em linha], [Consult. 31 mai. 2018], disponível na internet em WWW : <URL:http://bch.pt/ROA\%20III_IV\%202015.pdf;

HÖRSTER, Heinrich Ewald, "A parte geral do código civil português", 6.a reimpressão da edição de 1992, Coimbra, Almedina, 2011;

MARTINS, António Payam, "Class Actions em Portugal", Lisboa, Edições Cosmos, 1999;

MIRANDA, Jorge; MEDEIROS, Rui, "Constituição Portuguesa Anotada", Tomo I, 2. a edição, Coimbra, Coimbra Editora, 2010;

MIRANDA, Jorge, "Direitos Fundamentais", Coimbra, Almedina, 2016;

MONTEIRO, António Pedro Pinto; JúDICE, José Miguel, "Class actions \& Arbitration in the European Union-Portugal", em Estudos em Homenagem a Galvão Teles, Vol. II, Jorge Miranda (coord.) et al., Coimbra, Almedina, 2012, pp.189-205;

OTERO, Paulo, "A Ação Popular: configuração e valor no atual Direito português, Revista da Ordem dos Advogados, Lisboa, Ano 59, dez.1999, pp.871-893;

OTERO CRESPO, Marta, "Las acciones colectivas en Europa: ¿Un paso adelante?: Las líneas generales propuestas en la Recome ndación de la Comisión Europea sobre los principios comunes aplicables a los mecanismos de recurso colectivo de cesación o de indemnización en los Estados miembros en caso de violación de los derechos reconocidos por el Derecho de la Unión (2013/ 396/ UE)", Boletín Centro de Estudos e Documentación Europeos, Universidade de Santiago de Compostela, nov.2013;

REBELO, Marta, "A legitimidade popular para a efetivação de responsabilidades financeiras", em Estudos Jurídicos e Económicos em Homenagem ao Professor Doutor António de Sousa Franco, Vol. 
III, Paulo de Pitta e Cunha (coord.), Coimbra, Coimbra Editora, 2006, pp.285-299;

REIS, Rafael Vale e, "Collective Redress and Health Care Law: The Specific Characteristics of Group Compensation under Portuguese Law", em Collective Redress in Europe: Why and How?, Eva Lein, Duncan Fairgrieve, Marta Otero Crespo e Vincent Smith (ed.), BIICL, 2015; SOUSA, Miguel Teixeira de,

- $\quad$ "A Legitimidade Popular na Tutela dos Interesses Difusos, Lisboa, Lex, 2003;

- $\quad$ "Estudos Sobre o Novo Processo Civil", Lisboa, Lex, 1997;

- $\quad$ "Legitimidade Processual e Acção Popular no Direito do Ambiente", em Direito do Ambiente, Diogo Freitas do Amaral; Marta Tavares de Almeida (coord.), Oeiras, Instituto Nacional de Administração, 1994, pp.409-429. 